\title{
ESPACIALIDADES E INTERAÇÕES SOCIAIS: A AGÊNCIA DE REDES NA "FESTA DO PADROEIRO BOM JESUS" DA COMUNIDADE QUILOMBOLA DE SANTA CRUZ (PONTA GROSSA/PR)
}

\author{
TANIZE TOMASI \\ CICILIAN LUIZA LÖWEN SAHR \\ Universidade Estadual de Ponta Grossa
}

\section{Introdução}

As comunidades remanescentes de quilombos vivenciam na atualidade um momento de projeção nacional, seja pela via política ou acadêmica. A essa projeção se justapõe um processo atual de ressemantização conceitual do termo, o qual se desvincula da concepção enquanto resistência cultural, política e negra, para ser abordado em torno de três paradigmas: remanescentes, terras de uso comum e etnicidade. (Arruti, 2006).

Esses paradigmas representam pontos de fuga, uma estratégia de não capturar rótulos em um rol fixo de características, de forma a não referenciar os quilombos a um determinado estereótipo naturalista (raça) ou historicista (quilombos históricos) de como deveriam ser, o que excluiria a maioria dos casos concretos.

Dessa forma, deixam-se de lado as reminiscências históricas, para enfatizar as próprias comunidades e suas organizações sociais, destacando suas atuações políticas, suas constituições, sejam elas urbanas (quilombos urbanos) ou rurais, e a adesão a uma identidade étnica, que não está ligada à questão racial (cor da pele), e, sim, a uma referência histórica comum, construída a partir de vivências e valores partilhados (ABA, 1994). Permite-se ao grupo e ao indivíduo a autoatribuição, seja ela local ou jurídico-política (quilombola).

Essa forma de abordar os quilombos possibilita a análise do fenômeno a partir de sua manifestação local, definindo-o a partir dos dados da experiência em uma definição empírica e descritiva implícita, que não 
enumera elementos característicos. Essa é a definição fluída adotada para a construção das reflexões aqui apresentadas.

Este artigo tem por objetivo apreender a espacialidade da rede social da Comunidade Quilombola de Santa Cruz tomando por base o evento de interação social "Festa do Padroeiro Senhor Bom Jesus".

A comunidade está localizada no distrito de Guaragi, área rural do município de Ponta Grossa, na margem direita da PR-151 (Ponta GrossaPalmeira), mais especificamente no $\mathrm{km} 15$. Trata-se de uma comunidade relativamente pequena, constituída por 12 famílias que juntas vivenciam práticas tradicionais, como a festa do padroeiro, realizada anualmente no mês de agosto.

Tal evento de interação social, assim como outros, permitiu evidenciar a experiência relacional dos quilombolas de Santa Cruz com as comunidades circundantes, identificando os laços sociais que os ligam a outros indivíduos externos.

A existência de conexões em 'nó' permitiu, de um lado, compreender a dinâmica da vida cotidiana quilombola e, de outro, romper com a ideia de que os quilombos são comunidades isoladas, que não mantêm contato com o restante da sociedade.

Deste modo, tornou-se necessário além de identificar as relações sociais, apontar os atores e seus papéis durante o evento, analisando o ambiente/cenário onde foram protagonizadas as interações.

A metodologia empregada para o desenvolvimento desta pesquisa centrou-se nos fundamentos da 'Descrição densa', de Clifford Geertz e na 'Hermenêutica objetiva', de Ulrich Övermann.

Para Geertz (2011), a descrição densa apresenta-se sobre quatro características: a) ela é interpretativa; b) interpreta o fluxo do discurso social; c) a interpretação envolvida consiste em tentar salvar o 'dito' num tal discurso da sua possibilidade de extinguir-se e fixá-lo em formas pesquisáveis; d) ela é microscópica (estudos localizados).

A 'hermenêutica objetiva' consiste em “[...] uma proposta metodológica de coleta e análise de dados empíricos, desenvolvida e fundamentada na prática e não em categorias teóricas previamente elaboradas, cujo objetivo é a reconstrução do meio social pesquisado" (Weller, p. 8, 2007). Assim, ela é o entendimento do entendimento (Geertz, 1997). 
A coleta de dados deu-se através de relações dialógicas entre quilombolas e pesquisadores, auxiliadas por técnicas de pesquisa, como a realização de entrevistas aliada à história oral, a observação participante, a sistematização em diário de campo, bem como a captura de imagens visuais e audiovisuais, estas retrabalhadas em conjunto com os quilombolas para identificação dos indivíduos e de suas funções na festa.

A tais técnicas articulou-se a análise interacional, cuja abordagem perpassa os aspectos teórico-metodológicos desenvolvidos por Goffman (1985). Deu-se atenção à investigação da vida cotidiana, tomando a dinâmica das relações sociais interacionais que reproduz a realidade social do grupo estudado, esculpindo-a nos eventos interacionais. Neste caso, o evento escolhido é a Festa do Padroeiro.

As reflexões acerca da comunidade e do evento foram entrelaçadas aos conceitos de espaço/espacialidade, de Massey $(2004,2008)$ e Dardel (2011); de rede(s)social(is), de Scherer-Warren (2006) e Bott (1976); e de interação social de Goffman (1985). Esses conceitos possibilitaram pensar não apenas de forma realista e concreta sobre a comunidade, mas também de forma criativa e imaginativa com eles, de modo que o evento pôde ser aqui analiticamente reconstituído.

\section{Redes, interações e espacialidades sociais}

Os moradores da Comunidade Quilombola de Santa Cruz vivenciam uma complexidade de formas de interação social em rede, nas quais se tem um grupo de indivíduos inter-relacionando-se continuamente através do contato face a face em distintas situações de religião, trabalho, consanguinidade, festividade e filantropia.

Para que essas relações sociais possam ser compreendidas, utilizouse a abordagem de Scherer-Warren (2006), Lozares (1996) e Bott (1976), que veem tais relações sob a perspectiva de ações que têm certa continuidade, isto é, a manutenção de uma estrutura articulada de relacionamentos sociais, de contatos tecidos, de circuitos de interação (interna e externa) e de influência entre grupos nas suas experiências cotidianas.

Na abordagem de Scherer-Warren (2006):

Redes sociais, no sentido amplo, referem-se a uma comunidade de sentido, na qual os atores ou agentes sociais 
são considerados como os nós da rede, ligados entre si pelos laços dela, que se referem a tipos de interação com certa continuidade ou estruturação, tais como relações ou laços que se estruturam em torno de afinidades/identificações entre os membros ou objetivos comuns em torno de uma causa. Exemplos desses agrupamentos ou comunidades são as redes de parentesco, redes de amizade, redes comunitárias variadas (religiosas, recreativas, associativismo civil, etc.), contendo ou não uma organização formal. (Scherer-Warren, p. 2, 2006).

Para Lozares (1996, p. 108) as redes são como: “(...) un conjunto bien delimitado de actores - individuos, grupos, organizaciones, comunidades, sociedades globais, etc. - vinculados unos a otros a través de una relación o un conjunto de relaciones sociales".

Contudo, para Bott (1976), ao contrário de Scherer-Warren, as rede(s) social (is) não é/são uma comunidade, ou um conjunto bem delimitado no qual todos os indivíduos estão relacionados, como coloca Lozares. Para a autora, "A rede é definida como todas ou algumas unidades sociais (indivíduos ou grupos) com os quais um indivíduo particular ou um grupo está em contato" (Bott, p. 299, 1976).

Todavia, Bott (1976) comunga com o pensamento dos dois autores anteriores, quando aponta que as rede(s) espaço(s) são constituídas das relações sociais dos indivíduos na sua vida cotidiana, pelo contato face a face (Goffman, 1985), pela experiência humana (Dardel, 2011), e não organizados por uma luta política, mas simplesmente inter-relacionados ao mundo circundante pela espacialização humana (Massey, 2008).

Portanto, em vista do que foi exposto, adotam-se as definições abordadas pelos três autores, embora se aponte algumas discordâncias para duas das definições em relação à de Bott (1976), que passa a ser a mediadora entre as outras.

$\mathrm{O}$ conceito de rede(s) espaço(s) é tomado nesta pesquisa para tentar compreender os relacionamentos externos dos indivíduos no seu meio social, portanto, existe uma teia de relacionamentos que liga os seus membros por distintos laços sociais, sejam de amizade, parentesco, vizinhança ou em torno de uma causa, permitindo a manutenção de um contato (próximo ou mais distante) e que resulta na interação intensa ou moderada dos mesmos. 
Nesta pesquisa, as conexões sociais ligadas por laços de parentesco, amizade e vizinhança são as bases da organização social em forma de rede. Consideram-se essas relações de consanguinidade, afinidade ou vizinhança um dos mais seguros laços de relacionamento, constituindo-se em interações de continuidade/estruturação (Scherer-Warren, 2006) que permitem, segundo Goffman (1985), relacionamentos entre diversos atores em mais de uma situação social, em diferentes atividades/práticas sociais e nos mais variados cenários/ambientes.

Desta forma, acredita-se que as relações sociais em rede, que conectam os moradores quilombolas de Santa Cruz a indivíduos externos provocam diferentes espacialidades. Assim, adotam-se as reflexões em torno do conceito de espaço/espacialidade, acreditando que esse constitui a dimensão do social, elemento da existência humana e, portanto, resultado das relações sociais.

O espaço passa a ser pensado de forma alternativa, de modo a deixar as abordagens que o consideravam como uma superfície, contínuo e tido como algo dado, imóvel, para ser visto como algo interligado com o tempo e, assim, sempre mudando.

As abordagens do espaço como algo fixo levam a concepção dos lugares, povos e culturas simplesmente como fenômenos acontecendo sobre essa superfície. Desprovê-los de sua história, privando-os de suas próprias trajetórias, é deixá-los de fora da multiplicidade em que se vive, pois é o espaço que permite a construção das identidades, e nele ocorrem as interligações, de forma que nada possa ser inflexível (Massey, 2008).

Massey (2004, 2008) constitui sua abordagem de espaço/espacialidade em torno de três proposições. A primeira diz respeito ao reconhecimento do espaço como produto de inter-relações, instituído por meio de interações que podem ser multiescalares.

A segunda destaca-o como a esfera do encontro através de práticas e relações, da possibilidade da existência da multiplicidade, isto é, da pluralidade contemporânea em que as distintas trajetórias coexistem, e assim, a heterogeneidade humana se faz presente.

A terceira pensa o espaço/espacialidade como estando em continua construção, ativo, nunca acabado ou fechado, pois é produto de relações entre, relações que são práticas materiais necessariamente embutidas e que precisam ser efetivadas. Tais proposições vão de encontro à concepção de Goffman (1985), que descreve a interação social como o contato social de indivíduos no espaço. 
Portanto, o espaço não se apresenta de forma objetiva ou homogênea, mas sim marcado por valores heterogêneos e investido de direções significantes, pois é fruto da própria experiência humana (Dardel, 2011).

Desse modo, ele aparece essencialmente qualificado por uma situação concreta que afeta o homem, provando sua espacialização cotidiana, de afastamento e direção. Ambos definem a situação que extravasa para os domínios mais variados da experiência do mundo. "A 'situação' de um homem supõe um 'espaço' onde ele 'se move'; um conjunto de relações e de trocas; direções e distâncias que fixam de algum modo o lugar de sua existência" (Dardel, p. 14, 2011).

O espaço é, portanto, liberdade. Isso significa ter poder e espaço suficiente para atuar, pois "o espaço é experienciado quando há lugar para se mover" (Tuan, 1983, p. 13). A mobilidade humana coloca o espaço como a esfera do encontro (Massey, 2008), tecido pelos contatos face a face (Goffman, 1985). Assim, o espaço é produto de inter-relações, constituído através de interações e, dessa forma, ele nada mais é do que a soma das relações, interconexões, conexões e a ausência delas; ele também é absolutamente concreto (Dardel, 2011; Massey, 2008).

Entretanto, Massey enfatiza que "(...) existem sempre - em algum momento 'no tempo' - conexões ainda por serem realizadas, justaposições ainda por se transformarem em interações" (Massey, p. 8, 2008).

Desse modo, espaço e tempo estão relacionados, visto que espaço requer movimento, e este é tempo, pois, quando se move no espaço, também se avança ou se retrocede no tempo, e ele pode ser sentido e visualizado no espaço. Desta forma, espaço e tempo coexistem, entrelaçam-se, e cada um deles é definido de acordo com a experiência pessoal, considerando que toda atividade gera uma estrutura espaçotemporal especial (Massey, 2008).

Portanto, entende-se que tanto o espaço de Dardel quanto o de Massey não existem antes dos homens e de suas relações e, consequentemente, sem a sua experienciação, que resulta em uma espacialidade construída relacionalmente. Desta forma, busca-se apreender as especificidades desta espacialidade da rede social quilombola no evento "Festa do Padroeiro Senhor Bom Jesus" por meio do destaque da multiplicidade de 'nós' participantes e de 'nós' atores/executantes, ocupando o espaço onde se desenvolve o processo de interação social. 


\section{Interação social quilombola na perspectiva goffmaniana}

A espacialidade que, segundo Dardel (2011) e Massey (2008), é construída por meio das relações sociais e surge, de acordo com Goffman (2011), dos encontros/eventos de interação social durante uma determinada situação. Esta última é definida pelo autor como “(...) qualquer ambiente de possibilidades de monitoração mútua que dure pelo tempo em que dois ou mais indivíduos se encontrem na presença física imediata uns dos outros, e se estende por todo o território em que tal monitoração mútua é possível" (Massey, 2008, p. 159).

O evento é um meio viável para o processo de interação social, o qual permite que os indivíduos no desenvolvimento de práticas/atividades cotidianas, de lazer, de trabalho, etc. envolvam-se ou em contato face a face ou em contato mediado por outros participantes, em que sejam tomados pela "(...) influência recíproca dos indivíduos sobre as ações uns dos outros, quando, em presença física imediata” (Goffman, 1985, p. 23).

Nesse contexto, Goffman (1985) destaca que a definição da situação acontecerá conforme as ações desenvolvidas, pois estas são configuradas de acordo com os papéis por eles representados durante o desenvolvimento de uma determinada atividade/prática social. Assim, cada papel servirá para definir a situação, já que ele estabelece linhas de ação, destacando a melhor maneira de agir durante um evento de interação social. Tais eventos são tomados com a intenção de levar o indivíduo/ator a dar a impressão que o seu papel requer/permite.

Dessa forma, cada indivíduo presente na interação procurará agir de forma que suas expressões transmitam uma visão de definição da situação que julgar ser aceitável pelos outros. Porém, quando se trata de um evento coletivo, como no caso em estudo, os distintos papéis despenhados pelos diferentes atores serão realizados conforme o que pensa o grupo social.

Os participantes executores constituem um grupo de indivíduos que coopera na execução de uma rotina particular. Eles contribuem para uma única definição geral da situação, fazendo um acordo real sobre as pretensões do grupo que serão temporariamente acatadas por um consenso geral estabelecido num cenário de interação, evitando-se conflitos.

Ao adotar um determinado papel, o indivíduo passa a desenvolver determinada prática, a qual é conceituada por Goffman (1985) como o padrão de ação pré-estabelecido que pode ser executada em mais de uma ocasião. Assim, a adoção de papéis pelos indivíduos estabelece a simetria 
do processo de comunicação e monta o palco (com seu cenário) para um tipo de jogo de informação.

Diante disso, entende-se que papel social é a “(...) promulgação de direitos e deveres ligados a uma determinada situação social" (Goffman, 1985 , p. 24). Esse poderá envolver uma ou mais práticas, que podem ser executadas pelo ator numa série de oportunidades diante dos mesmos indivíduos ou para novos.

No entanto, quando um indivíduo/ator desempenha a mesma prática para um mesmo grupo de indivíduos em diferentes ocasiões, há a probabilidade de surgir um relacionamento social. Esse possibilita a constituição de rede(s) social(is), em que existe a conexão dos indivíduos, de acordo com Scherer-Warren (2006), com certa estruturação/continuidade. Diversas situações de interação social colocam estes indivíduos ou grupos de indivíduos em contato (Bott, 1976), de forma que haja um conjunto de relações e de trocas, vivenciados pela mobilidade humana no espaço (Dardel, 2011).

Quando o indivíduo/ator desempenha um papel, o mesmo está integrado em um cenário, que de acordo com Goffman (2011), compreende a mobília, a decoração, a disposição física e outros elementos que servem de pano de fundo para dar suporte ao desenrolar da ação humana executada diante, dentro ou acima dele. O cenário tende a permanecer fixo, de modo que aqueles que o usem para o desenvolvimento de uma atividade não possam começar sem terem-se colocado no lugar adequado e deixá-lo ao terminá-la.

Porém, há circunstâncias excepcionais onde o cenário acompanha os atores, como no caso da festa em estudo na qual, ao final da celebração da missa, realiza-se a procissão fora da capela e parte do cenário acompanha os atores e os participantes, o que o torna móvel.

É nesse contexto que Goffman (1985) parte da análise da investigação da vida cotidiana, comparando-a a um teatro, onde os indivíduos adotam papéis sociais e desenvolvem determinadas práticas sociais durante situações de interação. Essa análise permitiu manifestar a estrutura/organização social que o grupo quilombola apresentou num evento social tradicional de frequência anual. Deixou-se aqui de lado a abordagem religiosa da Festa do Padroeiro, para analisar o evento como um processo de interação social, visualizando as ações dos indivíduos na realização das práticas/atividades durante o mesmo. 


\section{Redes de interação social}

A Comunidade Quilombola de Santa Cruz é relativamente pequena. Constituída de 12 famílias, seis são católicas, duas são luterano-católicas, duas candomblista/umbandista-católicas, uma católico-evangélica e uma candomblista/umbandista. Contudo, de forma mais ou menos intensa, a administração da capela da comunidade dá-se através destas famílias, as quais vêm garantindo a manutenção do espaço há aproximadamente 70 anos. Assim, juntas, as famílias quilombolas vivenciam práticas tradicionais de interações sociais ligadas à religiosidade católica, como na festa de seu padroeiro.

Denominada "Capela do Senhor Bom Jesus", ela integra-se à Paróquia Espírito Santo, coordenada pela igreja São Vendelino no bairro Colônia Dona Luiza, pertencente à diocese de Ponta Grossa. Todo segundo domingo de cada mês, um diácono da paróquia Espírito Santo realiza missa na capela da comunidade e, no quarto domingo, essa é celebrada pelo padre da paróquia. Nos domingos restantes, os eventos religiosos ficam a cargo de uma ministra da comunidade.

Nessa capela, no mês de agosto de cada ano, realiza-se um evento de interação social que reúne um grande número de pessoas: a "Festa do Padroeiro Senhor Bom Jesus". Em 2011, o evento ocorreu no primeiro domingo do referido mês, no dia 07 . O evento deu-se em quatro distintos cenários: a 'capela', o 'coreto de música', o 'quiosque de bebidas' e o 'pavilhão de festas' (Figura 01). Esses abrigaram variadas práticas/atividades que foram desenvolvidas por uma série de atores, os quais desempenharam diferentes papéis no transcorrer do evento.
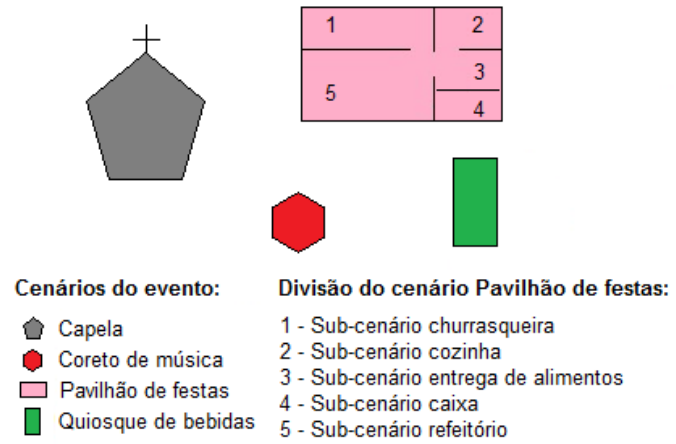

Figura 01 - Cenários do evento "Festa do Padroeiro Bom Jesus": Comunidade Quilombola de Santa Cruz (Ponta Grossa/PR) Org.: Os autores 
Deste modo, a 'capela' torna-se o primeiro cenário do evento de interação social a ser analisado. Para tanto, é preciso relembrar que o cenário, segundo Goffman (1985), é o equipamento expressivo do ambiente e serve como pano de fundo no desenrolar de uma ação humana, portanto, torna-se necessário descrever esse cenário com todos os seus elementos constituintes.

Pintada em azul, com detalhes em bordô, a capela é totalmente construída em madeira, incluindo paredes, forro, assoalho, janelas e porta. Um muro pré-moldado em cimento circunda toda a construção, permitindo o seu acesso por meio de um portão de madeira em duas folhas. Seu telhado é coberto com telhas de barro do tipo francesa, no qual se destaca uma pequena cruz na cumeeira frontal.

A parte interior deste cenário é composta por sete fileiras duplas de bancos com genuflexórios, um altar, um púlpito, uma mesa para o ofertório, um banco simples e duas cadeiras, todo esse mobiliário é feito em madeira. Adornando esta composição, têm-se uma cruz portando a imagem de Jesus Cristo, um mastro sustentando a bandeira vermelha com fitas amarelas do Divino Espírito Santo, dois pedestais amparando os vasos de flores naturais e um oratório abrigando as imagens de santos: do lado direito, a imagem do Divino Espírito Santo e da Mãe da Divina Graça, ao centro, São José e o Bom Jesus envolto em manto vermelho, ao lado esquerdo, Nossa Senhora de Fátima e São Benedito, além de velas e crisântemos naturais de várias cores.

As paredes internas comportam quadros e cartazes com temáticas religiosas. Na parede frontal, têm-se dois quadros com as imagens de Jesus Cristo e Virgem Maria. Nas paredes laterais, têm-se as 14 imagens das estações da Via Sacra. Próximo à porta da entrada da capela, encontra-se uma gamela de pedra feita pelos antepassados escravos que viveram na Fazenda Santa Cruz, a qual deu origem à comunidade. Atualmente, a gamela é utilizada como recipiente para água benta.

Na parte externa da capela, há ainda um sino de ferro alocado em dois pilares de cimento, protegido com um pequeno telhado de duas águas cobertos com telhas de barro. Dois cruzeiros compõem também este cenário, um intramuros, cravado ao lado direito da capela, e outro extramuros, no lado esquerdo da mesma.

$\mathrm{O}$ cenário 'capela' estava sendo utilizado quando chegamos à Comunidade Quilombola de Santa Cruz, por volta das 8:00 horas, para observação participante do evento. A capela estava aberta e havia uma movimentação de atores na mesma. Tratava-se apenas de mulheres: R. F. 
de A. B, a ministra da comunidade, T. C. B. filha dela, V. L. B, a presidente da Comissão da Capela, e E. B, quilombola da comunidade vizinha de Sutil ${ }^{1}$, ligada a Santa Cruz por laços de parentesco. Essas foram as primeiras atrizes destacadas e, portanto, seus papéis e suas atividades foram os primeiros a serem abordados, pois procurou-se seguir a ordem temporal do próprio evento. Assim, ao passo que os papéis, atores e atividades foram sendo observados no evento, eles foram sendo apreendidos e analisados.

V. L. B., moradora quilombola de 67 anos, viúva e mãe de dois filhos, é presidente da Comissão da Capela, cargo este com pleito de dois anos. Trata-se da pessoa responsável pela coordenação do evento, Festa do Padroeiro no ano em análise. Ela acumula este cargo paralelamente com o de vice-presidente da "Associação da Comunidade Negra Rural de Santa Cruz", ligada à questão fundiária.

V. L. B., T. C. B. e E. B., sob a coordenação da primeira, arrumavam os 'andores', que se constituem em padiolas ornamentadas para levar as imagens de santos durante a procissão, atividade realizada na parte final da missa. Todos os anos essa prática vem sendo desenvolvida, tendo V. L. B. como principal protagonista.

Quatro andores de madeira foram revestidos em cetim, três deles na cor vermelha e um no formato de barco, em branco. Os andores foram adornados com flores artificiais nas cores: rosa, laranja, vermelho e branco. Aos pés das imagens de São Benedito, Divino Espírito Santo, Nossa Senhora Aparecida e Bom Jesus foram amarradas fitas brancas. Tais andores representam elementos expressivos que são inseridos ao cenário 'capela' no dia do evento. Durante a missa, os andores ocuparam os últimos bancos, ficando sobre os mesmos até a hora da procissão.

R. F. de A. B., mulher de 44 anos e pertencente à comunidade quilombola, é casada com J. V. B., juntos eles têm uma filha, T. C. B., adolescente de 14 anos, que auxiliou na atividade de ornamentação dos andores. R. F. de A. B. vem atuando no papel de ministra na comunidade há dois anos, quando concluiu sua formação para esta função e passou a realizar a prática dos cultos nos domingos em que não há a presença dos representantes da paróquia (diácono ou padre). Ela é também responsável

A Comunidade Quilombola de Sutil é vizinha a de Santa Cruz, localizando-se cerca de 4 $\mathrm{km}$ da mesma. Até a década de 1980, segundo relato dos moradores, ambas constituíam-se em uma única, fruto dos antepassados escravos que trabalhavam na Fazenda Santa Cruz, que compreendia grande parte das terras da região. 
pela administração da coleta do dízimo e das doações. Há cinco anos vem executando ainda a compra de materiais para a capela, sua limpeza e guarda da chave, além de desempenhar o papel de catequista, juntamente com outros moradores da comunidade.

No mesmo horário em que as outras mulheres estavam desempenhando a atividade de ornamentação dos andores, ela cuidava da arrumação da capela, trocando as toalhas do altar por toalhas temáticas, isto é, com a imagem do Senhor Bom Jesus, padroeiro da festa, bem como enfeitava o oratório com flores naturais. No dia anterior, ela já havia realizado a limpeza do local.

A missa iniciou-se às 10:00 horas com a chegada de novos atores destaques do evento, o padre e a coordenadora de catequese da paróquia. Nesse ano, a missa foi celebrada pelo padre W. B. Ele é indiano e há cerca de um ano vem servindo a paróquia Espírito Santo e, dessa forma, também à Comunidade Quilombola de Santa Cruz. Ao longo da missa, Lx., a coordenadora de catequese da paróquia, desempenhou o papel de leitora nas atividades litúrgicas. Nessa atividade, também se evidenciaram outros atores, tais como A. de J. K., E. P., D. P. e C. B.

.A. de J. K., homem de 61 anos, solteiro, dedicava-se até pouco tempo às atividades de ministro, contudo, tal função passou a ser assumida por R. F. de A. B. Desta forma, ele desempenha os papéis sociais de catequista e leitor litúrgico, ajudando na realização dos eventos religiosos na capela. Ele atua também na Comissão da Capela.

C. B., casada com C. A. B. e mãe de três filhos, também auxilia na prática litúrgica e no coral em encontros religiosos na comunidade.

D. P. e E. P., mãe e filha, são moradoras externas da comunidade, vivem no bairro Cará-Cará, na cidade de Ponta Grossa. Ambas, segundo relatos dos moradores, participam assiduamente do evento Festa do Padroeiro. Essas, no respectivo ano, desempenharam papéis em atividades litúrgicas. Elas ligam-se aos moradores da comunidade por laços de vizinhança e afinidade/amizade, pois D. P. morou durante 20 anos com seus familiares próximo à comunidade. Atualmente, E. P. frequenta a catequese na comunidade e D. P., sua mãe, exerce o cargo de tesoureira da Comissão da Capela.

Por volta das 11:00 horas, na parte final da missa, deu-se início à atividade da procissão, que consiste em um cortejo religioso às imagens de santos. A procissão foi aberta pela bandeira do Divino Espírito Santo carregada por Lx., a coordenadora paroquial da catequese que, nesse 
momento, desempenhou uma nova atividade. Junto a ela uniu-se A. de J. $\mathrm{K}$., ator que também assumiu uma nova atividade carregando a cruz de Jesus Cristo. A eles, seguiram-se os andores carregados por voluntários que estavam acompanhando a missa. Normalmente, esses são pessoas que fizeram promessas.

O andor de São Benedito foi carregado por E. P. e sua mãe, D. P., ambas realizando uma nova atividade durante o evento. Esse andor veio logo atrás da bandeira vermelha do Divino e da cruz de Jesus Cristo, abrindo a procissão. Segundo relatos de V. L. B., todas as vezes em que São Benedito não abriu a procissão, alguma coisa ruim aconteceu, como na vez em que repentinamente começou um temporal ou no dia em que quebrou a escada de acesso à capela.

A ele, seguiu-se o andor do Divino Espírito Santo, carregado por L. P. (mãe de D. P.), antiga vizinha da comunidade, atualmente integrante da Comissão da Capela e moradora do bairro Cará-Cará, e por Ly., morador da vizinha Comunidade do Tabuleiro. Esse participou do evento com os pais e irmão, que inclusive participam regularmente dos cultos e missas na comunidade.

A Nossa Senhora Aparecida, colocada sobre o andor em formato de barco, foi carregada por quatro moradores da Comunidade do Tabuleiro: I. K., S., pai de Ly., e F. O local concentra entre os moradores descendentes de italianos. Os moradores do Tabuleiro participam regularmente dos eventos religiosos em Santa Cruz, pois são associados à capela.

Por último, seguiu o andor do padroeiro, com a imagem do Senhor Bom Jesus. Esse foi levado por quatro pessoas externas à comunidade: I. K. e R. K., moradoras da Comunidade do Tabuleiro, e, ainda, por R. do bairro Maria Otília, da cidade de Ponta Grossa, e um homem desconhecido. Acompanhando os andores, todos os participantes da missa seguiram em procissão. Dessa forma, pode-se perceber que nessas atividades desenvolvidas no cenário 'capela' os laços que ligam os elos na rede social quilombola são, na maioria dos casos, de vizinhança e amizade/afinidade.

A procissão circundou todos os cenários do evento, terminando ao adentrar novamente na capela, quando o padre finalizou a celebração litúrgica. Durante sua execução, ao passo que a bandeira, a cruz e os andores iam se movimentando, o padre W. B. e o restante dos acompanhantes iam entoando rezas e cantos. Nos cânticos, observou-se o destaque de uma nova atriz, E.. Ela é moradora da Comunidade do Tabuleiro e participa, junto com a família, dos encontros religiosos na 
capela, compondo o coral e ajudando nos cantos durante os cultos e missas. Esse elo da rede, também se liga por laços de vizinhança e afinidade.

Ao término da missa, outros cenários passaram a destacar-se, ocupados pelos participantes do evento e revelando outros atores, papéis e atividades. Um deles é o cenário "quiosque de bebidas" (Figura 01), que consiste em um cômodo de meia-parede, a qual desempenha a função de balcão e circunda toda a construção. Seis pilares, um em cada canto e dois no centro das laterais, sustentam o telhado com estrutura de madeira e telhas de cimento amianto. Dentro do pavilhão, encontrava-se apenas um congelador, que posteriormente abrigou as bebidas.

Esse cenário ganhou ênfase no evento em dois momentos, tanto na fase de preparação, quanto durante a realização do mesmo. $\mathrm{O}$ primeiro, anterior à chegada dos participantes, deu-se entre 8:00 e 9:00 horas, pois, enquanto as mulheres desenvolviam atividades na capela, chegava o caminhão de uma distribuidora de bebidas da cidade de Ponta Grossa.

V. L. B., que estava na capela, fez-se presente para o acompanhamento da atividade de descarregamento das bebidas e alocação das mesmas no quiosque. Posteriormente, a atividade foi acompanhada por uma nova atriz, A. B. da C., mulher de 29 anos, advogada, solteira e moradora da comunidade juntamente com seus quatro irmãos, uma vez que seus pais já são falecidos. Ela também é integrante da Comissão da Capela. No dia do evento, desempenhou ainda o papel de fiscal, conferindo e contando os fardos de bebidas que iam sendo descarregados. Nessa mesma atividade, um novo ator insere-se, P., responsável pelo transporte e alocação das bebidas e do gelo na comunidade. Ele começou a participar da festa nos dois últimos anos, quando a atual presidente passou a contratar os serviços da distribuidora em que ele trabalha.

$\mathrm{O}$ segundo momento de ênfase deste cenário iniciou-se às 11:00 horas, estendendo-se até o final do evento, às 20:00 horas. A atividade de entrega das bebidas aos participantes foi exercida por P.. A ele, juntaramse os atores J. V. B. e F. R. M. para desenvolver a atividade. Assim, P. liga-se aos elos da Comunidade Quilombola de Santa Cruz por laços em torno de uma mesma causa, ou seja, a venda das bebidas, pois para ele esta atividade torna-se parte integrante do trabalho que já desempenha. Esse cenário manteve-se, durante todo evento, rodeado por participantes, principalmente por homens.

J. V. B., homem quilombola de 56 anos, casado com R. F. de A. B. e pai de T. C. B., nesse dia exerceu o papel de entregador de bebidas durante todo o evento. No dia anterior, havia assumido o papel de jardineiro, 
cortando o gramado circundante aos quatro cenários. Ele teve auxílio de outro ator, F. R. M., adolescente quilombola de 16 anos, filho de V. L. B., a presidente da Comissão da Capela. Portanto, há nesse cenário a maioria dos elos ligados por laços de parentesco, uma vez que são, sobretudo, elos internos.

O terceiro cenário evidenciado no evento foi o 'pavilhão de festas'. Este ambiente também foi cenário de atores, papéis e atividades em dois momentos. Trata-se de uma construção em alvenaria, com piso de cimento e telhado com estrutura de madeira coberta por telhas de barro, a qual está divida em cinco subcenários: a 'churrasqueira', a 'cozinha', a 'entrega de alimentos', o 'caixa' e o 'refeitório' (Figura 01).

O subcenário 'churrasqueira' fica em uma das extremidades da construção, na parte posterior, separado da cozinha por uma parede em alvenaria e do refeitório por uma bancada de cimento de um metro de altura. Essa bancada serve para o atendimento aos participantes e para a entrega da carne já assada para os compradores. No lado oposto da bancada, ao longo de toda a parede, há três grandes churrasqueiras feitas com tijolo de barro e concreto, pintadas com cal.

No subcenário 'churrasqueira', antes do horário do almoço, J. V. B. e F. R. M., atores já citados anteriormente, encarregaram-se do papel de lenhadores, desenvolvendo a atividade de coleta e corte de grandes troncos de lenha trazidos das matas da comunidade. A lenha produzida por eles foi depositada próxima às churrasqueiras e no interior das mesmas, servindo posteriormente para a atividade de assar carne. Ambos são elos internos ligados por laços de parentesco.

A atividade de assar carne deu-se no horário entre 12:00 e 14:00 horas. Ela trouxe a exclusividade de abrigar somente atores externos à comunidade, os quais cumpriram o papel de assadores, cuidando do fogo e da carne, além da entrega do produto aos compradores. C. e M., cunhados, são moradores vizinhos da localidade de Faxinal dos Polacos, e os primos G. e R. (este último irmão de M.), são moradores da Comunidade do Tabuleiro. Todos participaram ativamente como churrasqueiros. C., além de atuar no papel de assador no dia do evento, ainda encarregou-se do papel de comprar a carne na semana anterior, a qual adveio das cidades de Ponta Grossa e Guarapuava.

Segundo relatos dos moradores quilombolas, a execução de ambas as atividades são fruto da predisposição dos vizinhos, sendo que estas anteriormente eram exercidas por seus pais. Esses atores evidenciam a ligação de elos na rede social por laços de vizinhança. 
A 'cozinha' é o segundo subcenário do 'pavilhão de festas'. Esse subcenário é composto por um fogão de chapa de ferro construído em alvenaria revestida de azulejos, uma pia com cuba sobre uma estrutura de madeira e uma mesa de madeira, a qual abrigava os principais condimentos e alimentos. Em uma de suas extremidades, ocupando toda uma parede, um balcão de alvenaria com uma bancada de granitina que servia para depósito das embalagens (pratos e copos descartáveis) e de utensílios (panelas, pratos e tampas).

Nesse subcenário destacou-se o papel de cozinheira. O preparo dos alimentos foi realizado por duas atrizes que já se fizeram presentes anteriormente no cenário 'capela', atuando na atividade ornamentação dos andores. Trata-se de V. L. B., moradora da própria comunidade, e E. B., moradora da Comunidade Quilombola do Sutil, ligada aos elos internos por laços de parentesco.

Os acompanhamentos do churrasco foram saladas de batata, tomate e cebola, além de arroz, farofa e pão. Para o lanche da tarde, foram confeccionados pastéis e cachorros-quentes. Bolos recheados também compuseram o cardápio, os quais foram fruto de doações de duas atrizes externas, O., moradora da Comunidade do Tabuleiro que todos os anos faz essa caridade, e nesse ano, destacou-se também C., quilombola da Comunidade do Sutil. Ambas ligadas por laços de vizinhança e afinidade.

O subcenário 'caixa' consiste em um pequeno cômodo, no qual há uma grande janela que fica de frente ao refeitório. Nele, os participantes compravam fichas tanto para as bebidas, quanto para os alimentos. O papel aí evidenciado é o de operadora de caixa, o qual foi executado por A. B. da C., anteriormente citada no papel de fiscal na entrega das bebidas. No dia do evento, ela também exerceu o papel de motorista, transportando os produtos comprados até o local da festa.

Entre os subcenários 'cozinha' e 'caixa', encontra-se o subcenário 'entrega de alimentos'. Nesse ficaram os produtos a serem comprados pelos participantes. O papel de recolhedor de fichas e entregador dos alimentos foi assumido por V. L. B., já citada em diversas das atividades anteriores, bem como, por A. A. de J. B. J. e S..

A. A. de J. B. J., adolescente de 16 anos, é filho de A. de J. B., líder quilombola presidente da "Associação da Comunidade Negra Rural de Santa Cruz". Pai e filho não são moradores da comunidade, vivem na cidade Ponta Grossa, mas consideram-se e são considerados como parte do grupo quilombola de Santa Cruz. Segundo relato dos moradores, normalmente eles não são participantes da festa em virtude de serem 
candomblistas/umbandistas e participarem de outro evento religioso. Como no presente ano V. L. B., irmã de A. de J. B., estava na presidência da Comissão da Capela e na coordenação da festa, A. A. de J. B. J., ligado por laços de parentesco, veio ajudar no evento. V. L. B., juntamente com os filhos e alguns moradores da comunidade, também participa e ajuda nas atividades ligadas ao Terreiro de Candomblé e Umbanda de A. de J. B. e sua esposa, contudo, alguns moradores mantêm certo estranhamento com a religião.

Porém, nesse ano, durante a realização da festa, houve um estreitamento da distância religiosa que separa líder quilombola de boa parte dos moradores, com a permissão de envio do filho ao evento.

S., mulher de aproximadamente 45 anos, irmã de F.,anteriormente citada no cenário 'capela', também é moradora da Comunidade do Tabuleiro. Além de participar nas missas e ajudar nas atividades litúrgicas na "Capela do Senhor Bom Jesus", ajudou no evento atuando na entrega dos alimentos aos participantes. Portanto, liga-se à comunidade por laços de vizinhança/amizade.

Por fim, o último subcenário é o 'refeitório', que compreende a maior parte do ambiente do cenário 'pavilhão de festas'. Nele, encontramse três fileiras de mesas e bancos de madeira. Num momento anterior à festa, próximo as 9:00 horas da manhã, T. C. B. e E. B., já mencionadas em outra atividade, executaram a arrumação das mesas, estendendo toalhas.

Num segundo momento, próximo das 12:00 horas, esse ambiente passou a ser ocupado pelos participantes, que foram organizando seus utensílios, como pratos, talheres, bandejas e condimentos trazidos de casa, pois a comunidade não dispõe desses. Assim, gradativamente, os participantes foram realizando suas refeições e, ao passo que uns iam terminando, outros passavam a ocupá-lo. Ao longo de todo o evento esse subcenário foi ocupado pelos participantes, que mesmo após a refeição, continuavam sentados nos bancos conversando.

Após as 15:00 horas, um novo cenário sobressaiu, o 'coreto de música'. Trata-se de uma construção de alvenaria no formato hexagonal, pintada a cal, onde seis pilares azuis sustentam o telhado com estrutura de madeira, coberto por telhas de cimento amianto. Ele está localizado entre os cenários 'capela' e 'quiosque de bebidas', em frente ao cenário ‘pavilhão de festas' (Figura 01). 
O 'coreto' abrigou três atividades: o leilão, a música e o bingo. A primeira atividade iniciou-se às 15:00 horas, quando o ator Z., subiu ao palco, assumindo, como nos anos anteriores, o papel de leiloeiro. Ele é morador da vizinha Comunidade Quilombola do Sutil e liga-se a Santa Cruz por laços de vizinhança. Para a prática do leilão, foram arrecadados os seguintes produtos: saco de batatas, bolo recheado, bebidas alcoólicas e galinha viva.

O leiloeiro ficou a maior parte do tempo circulando entre os participantes, anunciando no microfone o último valor ofertado à prenda $\mathrm{e}$ incentivando novos lances.

Essa prática foi intercalada com a atividade musical, cujos atores, integrantes de uma 'banda', passaram a ocupar o coreto e a desempenharem o papel de músicos até o final do evento. Tratou-se de três músicos, cada qual portando um instrumento, sendo eles: gaita, baixo e bateria. Eles executavam as atividades de cantar e tocar, perpassando por diferentes ritmos musicais. Nos últimos dois anos, essa banda foi contratada para animar o evento, ela é composta por músicos da Comunidade Quilombola do Sutil. Novamente os elos ligam-se por laços de vizinhança.

A terceira atividade foi o bingo, que se realizou a partir das 17:30 horas. Tal atividade teve como principal ator V. P., morador do bairro Cará-Cará na cidade de Ponta Grossa, também vizinho à comunidade, prevalecendo novamente os laços de vizinhança e amizade, pois V. P. é irmão de D. P. e filho de L. P., todos antigos moradores de localidades vizinhas. Para o bingo, o prêmio foi uma bicicleta doada por A. B. da C., que atuou como operadora de caixa, fiscal das bebidas e motorista. Sua doação foi fruto de promessa. Ela se apresenta como elo interno, sendo ligada por laços de parentesco.

Em todos os cenários havia tanto pessoas da comunidade quanto pessoas externas conhecidas dos moradores - ligadas por laços de amizade, parentesco e vizinhança -, e também pessoas totalmente desconhecidas desses, que vieram apreciar o evento. Assim, a configuração espacial da rede de interação social produzida no evento e em seus distintos cenários passa a ser foco de análise no próximo tópico. 


\section{Espacialidades das redes de interação social}

Os elos de redes são representados por atores ou agentes sociais. As redes sociais são ligadas por laços de parentesco, vizinhança ou amizade/afinidade. Tanto os 'nós' como os laços configuram e são configurados por espacialidades. No caso da Comunidade Quilombola Santa Cruz, os elos internos estabelecem-se, exclusivamente, por laços de parentesco. As atividades do evento Festa do Padroeiro, entretanto, na sua maioria, são desempenhadas com a inter-relação entre elos externos e internos. A espacialidade construída pelos 'elos executantes' nos diferentes subcenários pode ser visualizada na Figura 02.

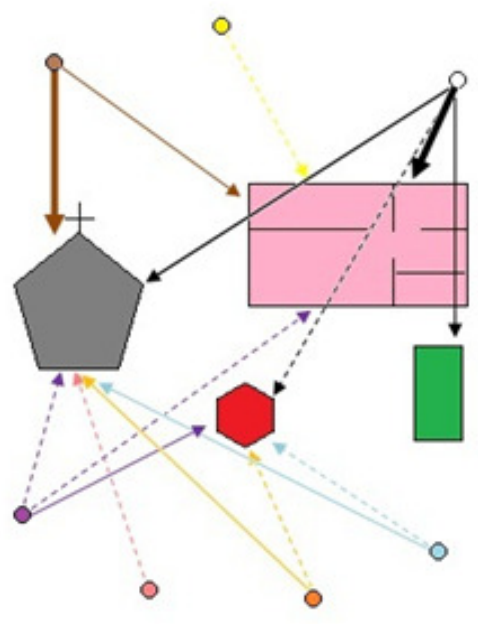

\section{Legenda}

Localidades de origem dos elos:

- Comunidade Q. de Santa Cruz

- Comunidade Q. do Sutil

- Comunidade do Tabuleiro

- Faxinal dos Polacos

- Bairro Cará-Cará

- Outros bairros de Ponta Grossa

- Desconhecidos

Quantidade de elos:

$\rightarrow 1$ a 2 pessoas

$\longrightarrow 3$ a 4 pessoas

$\longrightarrow 5$ a 6 pessoas

$\longrightarrow 7$ a 8 pessoas

Cenários do evento:

- Capela

- Coreto de música

$\square$ Pavilhão de festas

․ Quiosque de bebidas

Figura 02 - Espacialização dos 'elos executantes' das redes sociais do evento Festa do Padroeiro. Org.: Os autores

$\mathrm{Na}$ Festa do Padroeiro, apenas a atividade dos assadores foi realizada somente por 'elos executantes' externos, os quais atuaram no subcenário 'churrasqueira' sem inter-relação direta com elos internos. Os executantes eram provenientes do Tabuleiro e do Faxinal dos Polacos. 
Assim sendo, os elos provenientes da Comunidade do Tabuleiro construíram sua espacialidade no evento em torno dos cenários 'pavilhão de festas' e 'capela'. Já os elos da Comunidade Quilombola do Sutil tiveram sua espacialidade evidenciada em três cenários: 'capela', 'pavilhão de festas' e 'coreto de música'. Embora ambas as comunidades, Tabuleiro e Sutil, tenham se aproximado na variedade de atividades e papéis desenvolvidos por seus integrantes, os 'elos executantes' derivados da Comunidade do Tabuleiro apresentaram maior número.

Os 'elos executantes' do bairro Cará-Cará efetivaram sua espacialidade nos cenários 'capela' e 'coreto de música', por meio da atuação em três distintas atividades. Todavia, a espacialidade dos elos de outros bairros da cidade de Ponta Grossa também se deu no cenário 'capela', acrescentando ainda os cenários 'pavilhão de festas' e 'quiosque de bebidas', existindo, portanto, uma maior atuação e diversidade de papéis e atividades.

A espacialidade dos 'elos executantes' internos deu-se em todos os cenários e circundando os mesmos, no entanto, a quantidade de elos não foi tão significativa, mas, sim, o número de papéis e atividades desenvolvidas pelos mesmos. Quase todos atuaram em mais de um cenário em distintas atividades, algumas desempenhadas momentos antes da chegada dos participantes no evento. Contudo, o número de 'elos executantes' internos não supera a quantidade desses provenientes da Comunidade do Tabuleiro.

Todavia, quando se apreende apenas os 'elos participantes' do evento, sendo eles internos ou externos, deixando-se de lado os 'elos executantes', existe outra espacialidade dos fluxos da rede social (Figura 03). Há maior inclusão de elos externos originários de uma gama mais diversificada de locais, permitindo que esses relacionamentos evidenciem uma espacialidade constituída ainda mais pela multiplicidade e pluralidade das inter-relações. 


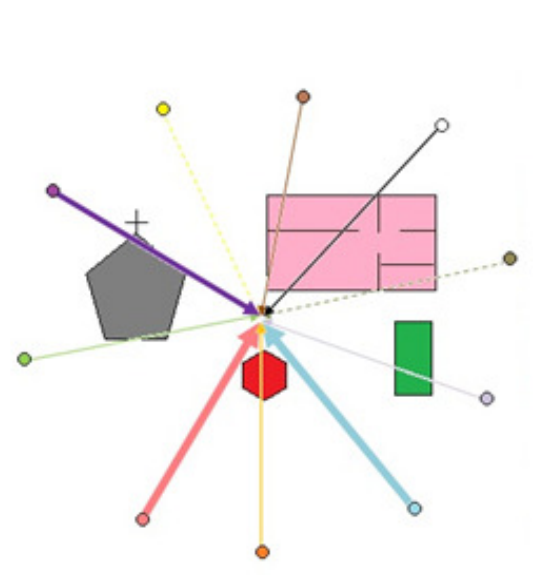

\section{Legenda}

Localidades de origem dos elos:

- Comunidade Q. de Santa Cruz

- Comunidade Q. do Sutil

- Comunidade do Tabuleiro

- Faxinal dos Polacos

- Colônia do Lago

- Colônia Santa Cruz II

- Vila Rural de Guaragi

- Bairro Cará-Cará

- Outros bairros de Ponta Grossa

- Desconhecidos

Quantidade de elos:

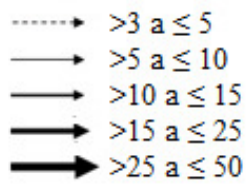

Cenários do evento:

\section{Capela}

Coreto de música

$\square$ Pavilhão de festas

Quiosque de bebidas

Figura 03 - Espacialização dos 'elos participantes' das redes sociais do evento Festa do Padroeiro. Org.: Os autores

Dessa forma, há a inserção de três novas localidades de origem dos elos do evento, Colônia Santa Cruz II, Vila Rural de Guaragi e Colônia do Lago, que se ligam por laços de vizinhança. Destacam-se na categoria desconhecidos, uma vez que os 'elos participantes' são pessoas com nenhum tipo de laço com os moradores de Santa Cruz, logo, seus locais de origem não são identificados pelos moradores da comunidade.

A Colônia Santa Cruz II é constituída por população de imigrantes bielo-russos, denominados russo-brancos, que mantêm relações de vizinhança com a comunidade não somente em momentos festivos, como o evento Festa do Padroeiro, mas de trabalho, em que há frequentemente a prestação de serviços pelos quilombolas. Anualmente, os moradores da colônia vêm participando da festa, no entanto, no referido ano apenas três 
pessoas participaram da mesma no período vespertino. Assim, destaca-se como o local de origem com menor número de 'elos participantes'.

O segundo local de origem com menor proporção foi o Faxinal dos 'Polacos', com apenas cinco participantes. Segundo os moradores de Santa Cruz, essa localidade é constituída por descendentes de poloneses e localiza-se próximo à Vila Rural de Guaragi. Trata-se de uma comunidade de faxinal que, no passado, caracterizava-se pela existência de criadouro coletivo sob Mata de Araucária.

Já a Colônia do Lago e a Vila Rural de Guaragi - a primeira formada por imigrantes russo-alemães e a segunda por populações de antigos faxinais e de comunidades rurais - fizeram-se representadas pela mesma quantidade de elos, 10 pessoas. Esses participam apenas desse evento de interação social em Santa Cruz. A Comunidade do Tabuleiro também esteve representada no evento por 10 participantes, contudo, os indivíduos dessa localidade participam intensamente dos eventos religiosos na capela da comunidade.

Na sequência, destaca-se o bairro Cará-Cará, com cerca de 15 participantes e moradores de Santa Cruz. Eles não executaram nenhuma atividade durante o evento, o que pode ser justificado pela não inclusão desses em nenhum cargo administrativo ou pela falta de afinidade com os atuais integrantes da Comissão da Capela.

Todavia, a Comunidade Quilombola do Sutil destaca-se na segunda posição de local de origem de maior intensidade dos fluxos, com aproximadamente 25 'elos participantes'. Essa realidade justifica-se não somente por laços de vizinhança ou afinidade/amizade, mas por laços de parentesco aos 'elos internos', o que os torna participantes assíduos desse e de outros eventos em Santa Cruz.

A inserção de 'elos participantes' desconhecidos pelos moradores de Santa Cruz deu-se na maior proporção, assim como, os elos provenientes de outros bairros da cidade de Ponta Grossa, cada qual totalizando cerca de 50 pessoas. Esses últimos, em muitos casos, apresentaram-se ligados aos 'elos internos' da comunidade por laços de parentesco.

Levando-se em consideração a apreensão de todos os indivíduos presentes no evento de interação social, tanto os 'elos executantes' quanto os 'elos participantes', e deixando-se de lado aqueles provenientes da área urbana de Ponta Grossa, a Tabela 01 apresenta uma tipificação das localidades de origem dos mesmos. Tais localidades correspondem a uma área circunvizinha à Comunidade Quilombola de Santa Cruz. 


\begin{tabular}{|c|c|c|c|c|}
\hline Tipologia & Nome & Localização & $\begin{array}{c}\text { Famíli } \\
\text { as }\end{array}$ & Descendência \\
\hline Comunidade & Tabuleiro & PR-438/151* & $16^{*}$ & $\begin{array}{l}\text { Luso-brasileiros }{ }^{* * * *} \mathrm{e} \\
\text { italianos }\end{array}$ \\
\hline Faxinal & "Polacos" & $\begin{array}{l}\text { Prox. Vila Rural (PR- } \\
151)^{*}\end{array}$ & $50^{*}$ & $\begin{array}{l}\text { Poloneses e } \\
\text { população cabocla* }\end{array}$ \\
\hline Vila Rural & Guaragi & $\begin{array}{l}\text { À } 8 \mathrm{~km} \text { da sede do distrito } \\
\text { de Guaragi, acesso pela } \\
\text { PR-438****}\end{array}$ & $100^{*}$ & $\begin{array}{l}\text { Habitantes de antigos } \\
\text { faxinais e } \\
\text { comunidades } \\
\text { rurais }^{\star \star \star \star}\end{array}$ \\
\hline Quilombo & Sutil & $\begin{array}{l}\text { PR-151 (abaixo } 4 \mathrm{~km} \text { de } \\
\text { Santa Cruz, margem } \\
\text { direita) }\end{array}$ & $\begin{array}{l}41^{\star \star \star \star *} \\
{ }^{*}\end{array}$ & Afro-brasileira** \\
\hline Colônia & $\begin{array}{l}\text { Santa } \\
\text { Cruz II }\end{array}$ & $\begin{array}{l}\text { PR-151 (margem } \\
\text { esquerda) }\end{array}$ & $12^{* * *}$ & $\begin{array}{l}\text { Imigrantes bielo- } \\
\text { russos (russo- } \\
\text { brancos) }\end{array}$ \\
\hline Colônia & Lago & $\begin{array}{l}\text { PR-151, } 14 \mathrm{~km} \text { de Santa } \\
\text { Cruz (nas duas } \\
\text { margens) }\end{array}$ & $70^{\star *}$ & $\begin{array}{l}\text { Imigrantes russo- } \\
\text { alemães }^{\star *}\end{array}$ \\
\hline
\end{tabular}

Tabela 01 - Caracterização da origem dos "elos executantes e participantes" do evento Festa do Padroeiro. Fonte: *Moradores da Comunidade Q. de Santa Cruz; **HARTUNG, 2000; ***ANTONELLI, 2008; ****CHEMIN et al. , 2002; *****MICELI, 2005; $* * * * * *$ GUARNERI, 2011.

Org.: Os autores

Com a apreensão de todas as atividades, papéis, atores e participantes do evento Festa do Padroeiro, pôde-se visualizar sua estrutura espaçotemporal, ou seja, suas distintas espacialidades e sucessões temporais (Figura 04).

O $1^{\circ}$. Momento deu-se entre 8:00 e 11:00 horas, que corresponde ao período imediatamente anterior e posterior à chegada dos participantes. Nesse, a espacialidade foi edificada em três cenários: 'capela', 'quiosque de bebidas' e 'pavilhão de festas', todavia, o destaque foi para o cenário 'capela', onde houve a celebração inicial do evento. Essa espacialidade reuniu atores e participantes nas atividades de ornamentação dos andores, 
fiscalização das bebidas, limpeza e arrumação da capela, corte de lenha, organização das mesas, realização da missa e procissão.

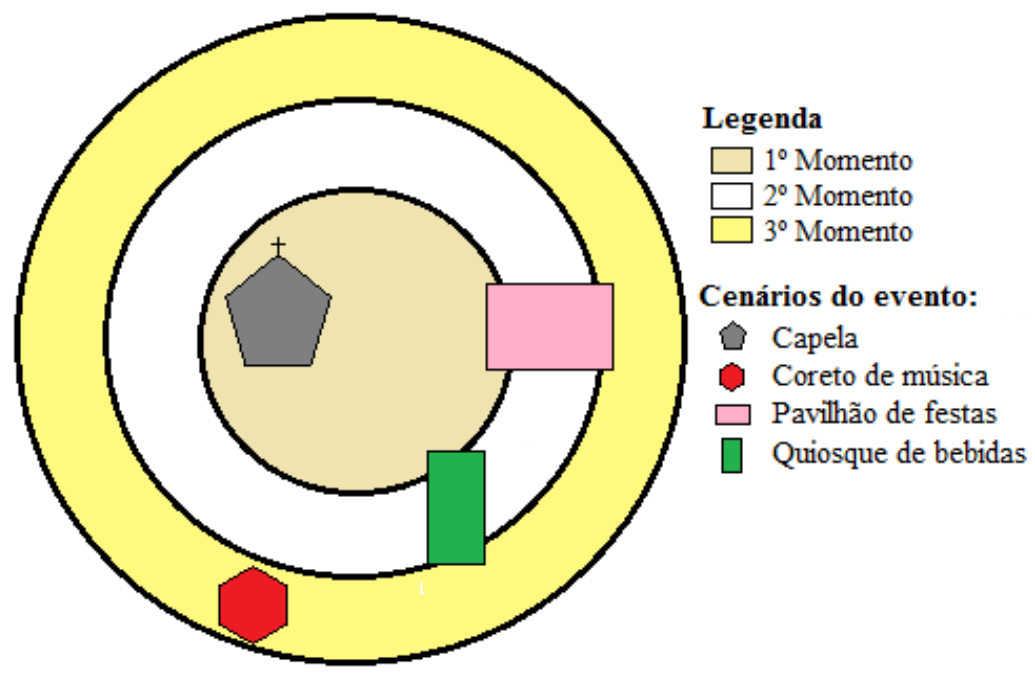

Figura 04 - Estrutura espaço-temporal do evento "Festa do Padroeiro Bom Jesus". Org.: Os autores

A atividade procissão encerrou o $1^{\circ}$. Momento, e o $2^{\circ}$. Momento estabeleceu-se no período entre 11:00 às 15:00 horas. A espacialidade foi construída em torno de dois cenários, 'pavilhão de festas' e 'quiosque de bebidas'. Neles foram executadas as seguintes atividades: elaboração dos alimentos, preparação e entrega do churrasco, venda de fichas de bebidas e alimentos e entrega dos produtos. No período final do evento, $3^{\circ}$. Momento, entre 15:00 e 20:00 horas, a espacialidade foi decorrente de três atividades: música, leilão e bingo. Nelas, os atores e participantes ocuparam os cenários 'pavilhão de festas' e 'quiosque de bebidas', que já vinham sendo utilizados no momento anterior, e também o cenário 'coreto de música', que foi o foco central desse último período temporal. 


\section{Considerações Finais}

A "Festa do Padroeiro Senhor Bom Jesus", embora seja um evento religioso, neste artigo foi tomada exclusivamente como um evento de interação social na perspectiva de Goffmann. Isso possibilitou a análise do evento em duas circunstâncias, de um lado, a do indivíduo e sua atuação particular, e, de outro, a do conjunto de participantes e executantes (internos e externos) e a interação como um todo, envolvida pelas relações sociais entre diferentes indivíduos (multiplicidade) no espaço (os quatro cenários). A articulação desse processo analítico conjunto, estruturado a partir das concepções de Massey, resultou na apreensão da espacialidade da rede social, constituída a partir da perspectiva da Comunidade Quilombola de Santa Cruz, bem como na visualização da estrutura espaçotemporal do evento.

A espacialidade foi apreendida através da identificação dos atores/indivíduos que executaram alguma atividade/prática social durante o evento e também pela identificação dos elos externos e internos que apenas participaram do mesmo. A espacialidade permitiu compreender que tal rede conectou os indivíduos por laços de parentesco, vizinhança ou amizade/afinidade.

Verificou-se que os indivíduos internos estabeleceram-se, exclusivamente, por laços de parentesco, visto que a comunidade é constituída por um grupo parental. Com relação aos indivíduos externos, a maioria desses ligou-se aos elos internos por laços de vizinhança/afinidade, uma vez que tanto os participantes quanto os indivíduos atuantes eram provenientes de localidades de uma área circunvizinha à comunidade.

Portanto, a espacialidade da rede social quilombola que se evidenciou durante o evento de interação apresentou-se não como uma rede isolada, mas localizada, uma vez que os indivíduos externos conectados pertencem a diferentes grupos étnicos de uma área rural circunvizinha, localizada nos municípios de Palmeira e Ponta Grossa. Grande parte desses já se conecta aos quilombolas por meio de outras redes sociais, como a de parentesco, amizades/afinidade, de vizinhança, de trabalho, de religião, entre outras.

Assim, a espacialidade configura-se como um processo aberto, de conexão de fora para dentro e de dentro para fora, em que os indivíduos pertencentes a localidades externas ligam-se aos indivíduos internos durante o evento de interação social promovido pela Comunidade Quilombola de Santa Cruz, reafirmando seus elos e 'nós'. 
ESPACIALIDADES E INTERAÇÕES SOCIAIS: A AGÊNCIA DE REDES NA "FESTA DO PADROEIRO BOM JESUS" DA COMUNIDADE QUILOMBOLA DE SANTA CRUZ (PONTA GROSSA/PR)

Resumo: Através de um evento de interação social, a Festa do Senhor Bom Jesus, buscou-se compreender a espacialidade das redes sociais na Comunidade Quilombola de Santa Cruz (Ponta Grossa/PR). Para isso, adotamos metodologias e técnicas pautadas nos fundamentos da 'Descrição densa', de Clifford Geertz e na 'Hermenêutica objetiva', de Ulrich Övermann. Essas foram entrelaçadas aos conceitos de espaço/espacialidade, de Doreen Massey (2004, 2008) e Eric Dardel (2011), de redes sociais, de Ilse Scherer-Warren (2006) e Elizabeth Bott (1976), e de interação social d'Erving Goffman (1985). Dessa forma, foi possível refletir sobre as espacialidades das redes sociais da comunidade enquanto produtos de inter-relações e da multiplicidade dos nós e laços das redes, salientando a constante abertura do processo a novas conexões.

Palavras-chave: Interação Social, Espacialidade, Redes Sociais, Comunidade Quilombola, Quilombo, Santa Cruz.

SOCIAL SPATIALITIES AND INTERACTIONS: THE AGENCY OF NETWORKS AT THE "PATRON'S FEAST OF THE GOOD JESUS" IN THE MAROON (QUILOMBOLA) COMMUNITY OF SANTA CRUZ (PONTA GROSSA/PR)

Abstract: To understand social networks in the maroon community of Santa Cruz (Ponta Grossa, Paraná), the social interactions of the community during its patron's feast of Good Jesus have been investigated. For this purpose, methodologies and research techniques of the so-called 'dense description' developed by Clifford Geertz and of the 'objective hermeneutics' proposed by Ulrich Övermann have been implemented. These have been interconnected to the concepts of space/spatialities of Doreen Massey $(2004,2008)$ and Eric Dardel (2011), social networks of Ilse Scherer-Warren (2006) and Elizabeth Bott (1976), and social interactions of Erving Goffman (1985). Thus, it was possible to investigate the social networks of the community as a result of interrelations, and of a multiplicity of knots and links in network structures, demonstrating its permanent openness for new connections.

Keywords: Social Interaction. Spatiality. Social Networks. Quilombola Communities. Maroon Communities. Quilombo Santa Cruz. 


\section{BIBLIOGRAFIA}

ABA - Associação Brasileira de Antropologia (1994). Regulamentação de Terras de Negro no Brasil. Boletim Informativo NUER, Florianópolis, n.1. (Boletim do grupo de trabalho sobre as comunidades Negras Rurais).

ANTONELLI, D. (2008). Em domínio russo. Curitiba: Imprensa Oficial. $84 \mathrm{p}$.

ARRUTI, J. M. (2006). Mocambo: Antropologia e História do processo de formação quilombola. Bauru/São Paulo: Edusc. 368 p.

BOTT, E. (1976). Família e rede social. Rio de Janeiro: F. Alves, 1976. $320 \mathrm{p}$.

CHEMIN, M. et al. (2002). Plano Diretor de Turismo de Ponta Grossa. Ponta Grossa: PMPG. 59p.

DARDEL, E. (2011). O Homem e a Terra: Natureza da Realidade Geográfica. São Paulo: Perspectiva. 159 p.

GEERTZ, C. (1997). O saber local: novos ensaios em antropologia interpretativa. Petrópolis: Vozes. 366 p.

. (2011). A interpretação das culturas. Rio de Janeiro: LTC.

$213 \mathrm{p}$.

GOFFMAN, E. (1985). A representação do eu na vida cotidiana. Petrópolis: Vozes. 236 p.

. (2011). Ritual de interação: ensaios sobre o comportamento face a face. Petrópolis: Vozes. $255 \mathrm{p}$.

GUARNERI, H. J. (2011). A dinâmica territorial na Comunidade Negra Rural de Sutil, municipío de Ponta Grossa - PR. 80 f. Trabalho de Conclusão de Curso (Graduação em Geografia Bacharelado). Universidade Estadual de Ponta Grossa, Ponta Grossa.

HARTUNG, M. F. (2000). A comunidade do Sutil: história e etnografia de um grupo negro na área rural do Paraná. 595 f. Tese (Doutorado em Antropologia Social) - Museu Nacional, Universidade Federal do Rio de Janeiro, Rio de Janeiro.

LOZARES, C. (1996). La teoria de redes sociales. Papers 48, Barcelona, p. 103-126.

MASSEY, D. (2004). Filosofia e política da espacialidade: algumas considerações. GEOgraphia, Rio de Janeiro, v. 6, n.12, p. 7-23.

. (2008). Pelo espaço: uma nova política da espacialidade. Rio de Janeiro: Bertrand Brasil. $311 \mathrm{p}$. 
MICELI, J. C. (2005). Construção do espaço social dos vileiros: a subjetividade do agricultor familiar nas Vilas Rurais do Paraná. 89 f. Dissertação (Mestrado em Geografia). Programa de Pós-Graduação em Geografia, Universidade Federal do Paraná, Curitiba.

SCHERER-WARREN, I. (2006). Das Ações Coletivas às Redes de Movimentos Sociais. In: NPMS/UFSC. Relatório do Núcleo de Pesquisa em Movimentos Sociais da UFSC. Florianópolis: UFSC, p. 1-18, 2006.

TUAN, Y. F. (1983). Espaço e Lugar: A perspectiva da Experiência. São Paulo: DIFEL. 250 p.

WELLER, W. (2007). A hermenêutica como método empírico de investigação. In: Anais da $30^{a}$ Reunião Anual da ANPEd, Caxambu. $30^{\mathrm{a}}$ Reunião Anual da ANPEd. p. 1-16. 